\title{
INFANCIA, SIGNIFICANTE EN FALTA DE SIGNIFICACIÓN'
}

\section{Mercedes Minnicelli}

\section{INFÂNCIA, SIGNIFICANTE EM FALTA DE SIGNIFICAC̣̃̃o}

RESUMO: Considerar o termo "infância" como um "significante sempre em falta de significação" permite-nos uma rede argumentativa sustentada no discurso psicanalítico, segundo a perspectiva de Giorgio Agamben, que coloca a infância em relação à linguagem. Ponto de partida para fazer a seguinte tese: A infância - como significante é, para a linguagem, o que o desejo é para a lei. Infância foi, é e será um significante sempre em falta de significação, instituindo-se pela linguagem e no campo da linguagem. $\mathrm{O}$ estatuto da legalidade subjetiva deve distinguir-se do código jurídico para poder colocar a tensão possível entre um e outro. É preciso esclarecer o sentido que damos ao termo instituição, distinguindo-o do sentido jurídico que ele recebeu e ainda conserva, propondo recuperar seu valor em termos de escritura da lei na constituição subjetiva, marco epistêmico que nos brinda a psicanálise.

Palavras-chave: Infância; Linguagem; Instituição

\section{CHILDHOOD, A SIGNIFIER LACKING SIGNIFICATION}

ABSTRACT: Considering the term "childhood" as a "signifier always lacking signification" enables us to establish an argumentative network supported by the psychoanalytical discourse. According to Giorgio Agamben, childhood is related to language, and this is the starting point for the following thesis: childhood - as a signifier - stands for language as desire stands for law. It was, is and will be a signifier always in lack of signification, establishing itself by language and in the field of language. The statute of the subjective legality must be distinguished from the judicial code enabling the enactment of a possible tension between them. The meaning given to the term institution must be cleared up: it should be distinguished from the legal sense it has been given and still retains, proposing a retrieval of its value in terms of the writing of law as subjective constitution, an epistemic landmark raised by psychoanalysis.

Keywords: Childhood; Language; Institution

Psicanalista; Doutora em Psicologia e Professora da Faculdade de Psicologia da Universidade Nacional de Mar del Plata - Argentina.E-mail: mercedes_minnicelli@hotmail.com 
Infancia es un término polisémico de amplia circulación en nuestros tiempos al cual consideramos un significante. En tanto tal, opera en el hablante y se hace presente en "dichos y decires" gracias a los que tanto se habla, como también se calla.

Desde esta perspectiva no podemos dejar de interrogarnos: ¿de qué "infancia" se habla cuando se habla de "infancia"? Su "polisemia" nos convoca a abrir el abanico de significaciones tanto en las distintas disciplinas que la toman como objeto de estudio como en los diferentes sentidos que adopte,

a) según se lo adjetive: Infancia abandonada, infancia perdida, infancia pobre, infancia rica, infancia instituida, infancia destituida; infancia judicializada; infancia pública; infancia burguesa; infancia proletaria; infancia moderna; infancias...

b) según se predique sobre ella, en tanto sujeto gramatical de la oración, da lugar a diversidad de definiciones.

Infancia admite diferentes posiciones gramaticales, pudiendo ubicarse tanto como sujeto, como predicado; admite ser adjetivada, como vimos más arriba, o derivar en adverbio (infantilmente).

En tanto objeto de estudio ha despertado amplio interés académico y político en nuestros días. Basta con recorrer los temarios de Jornadas y Congresos especializados e interdisciplinarios. Sin embargo, es importante señalar la diversidad de puntos de vista con que cada disciplina aborda la infancia. Esto nos permite afirmar, que decir infancia genera efectos diferenciales a partir de su ingreso en una cadena significante biográfica y colectiva.

Dicha polisemia no sólo abre el campo a las controversias y confusiones, sino que además acompaña al término desde los tiempos en que tenemos registro del pensamiento occidental, tal como con un interesante recorrido lo expone Kohan (2004). Más allá de esto, bien sabemos que aún no se resuelven los problemas que afectan a "eso" que generalmente se llama infancia cuando se homologa el término a niño/a.

Infancia y niño/a sólo son homologables en sentido general si consideramos a la infancia como un ciclo de la vida en términos cronológicos.

Eso llamado infancia no se deja apresar en concepto unívoco alguno. En tanto significante, oficia de término clave que hace entrar en juego la polisemia semántica. Tal efecto de discurso resulta interesante y curioso cuando, en su autonomía, el propio término -al ser escuchadoresuena en la singularidad biográfica. Es decir, infancia para cada uno sig- 
nificará de modo diferente, al disparar el juego de la lógica del significante, la puesta en movimiento de la cadena en la remisión a lo reprimido de la propia infancia.

En el discurso social -académico o no- resulta de difícil aprehensión una definición unificada de eso a lo cual se llama infancia, lo que da lugar a diferentes derivas discursivas y epistemes.

Los niños y las niñas están sujetos a las variantes históricas de significación de los imaginarios de época, en tanto a lo largo de la historia se han promovido dichos y decires de infancia y sobre ella. Estos se encuentran en discursos y prácticas que dan cuenta de discontinuidades y continuidades en los modos de considerar la niñez en distintas épocas, en diferentes culturas y en diversos discursos disciplinares.

Las "transformaciones" que se producen en las "verdades de época" (Samaja, 1993) definen momentos por sus marcas, por sus rasgos sobresalientes. Es decir, si se realiza un corte sincrónico en la continuidad diacrónica, es posible identificar lo característico de una determinada época. Amén de ello, en tanto acontecimientos sujetos al juego significante de la historia -expresado en discursos y prácticas hablantes y silentes que enuncian determinados "saberes" y prácticas respecto de los niños y niñas- en su repetición, aquello que se repite es único, es Uno y se abre con ese uno un conjunto de repeticiones por venir, que darán cuenta del juego de lo Uno y de lo múltiple.

Entonces, dichos y decires de y sobre la infancia puestos en la relación significante, expresan la tensión entre lo viejo y lo nuevo; entre tradición e innovación; entre continuidades y discontinuidades históricas que han estado y siguen estando presentes.

En cada tiempo socio-histórico, las nociones de infancia, de niñez, de niños y niñas se encuentran subordinadas a las controversias presentes en los enunciados filosóficos, educativos, legislativos, médicos, religiosos y, sobre todo, a las creencias y ficciones que sobre los niños y las niñas se formule una comunidad determinada.

En nuestros tiempos sólo la a-historicidad puede otorgarle estatuto de nuevo a lo que no es más que presencia, difusa en algunos casos, del retorno de rasgos e improntas de todos los tiempos. Como todo retorno de lo reprimido, se tratará de hallar en lo mismo lo distinto.

$\mathrm{Al}$ momento en que se escriben estas páginas, no podemos desestimar el valor que representa el hecho de que hoy la infancia busca ser hablada. Y ese estallido quizás se parezca aún más a un monólogo paralelo que a la búsqueda cierta de significaciones a partir de las cuales poda- 
mos, además de hablar, hacer algo que redunde en la disminución del sacrificio ${ }^{3}$ innecesario al cual son expuestas y se ofrecen las nuevas generaciones humanas.

A partir de las investigaciones historiográficas de Philippe Ariès (1973) la noción de infancia cobró en el circuito de legitimación académica, de modo hegemónico ${ }^{4}$, el estatuto de "moderna", lo que impactó de modo contundente en su definición y, así, pasó a ser punto de referencia y comparación en diversidad de trabajos respecto del tema. Al mismo tiempo, se configuró un campo de debate que comenzó a rebatir dichos fundamentos ${ }^{5}$.

Poco se habla de este debate y de las controversias que el concepto de infancia moderna provocara, incluso al mismo Ariès, cuando, por un trabajo que consideramos a-crítico y a-histórico, el producto de ciertas derivas epistémicas contemporáneas apuntan que

a) o bien la infancia es moderna o no es infancia y se declara su fin;

b) o bien la infancia no es moderna y hoy asistimos al fenómeno de nuevas infancias y adolescencias.

Estas improntas se traslucen en políticas, prácticas institucionales, intervenciones clínicas, sociales, judiciales; en spot publicitarios, en propuestas de "experiencias innovadoras" que toman a los niños y niñas como objeto del operador silencioso llamado mercado.

Desde la perspectiva propuesta, trabajar con el término infancia en tanto significante implica necesariamente considerar que, por su multivocidad, ocupa un lugar diferencial en la producción de sentido singular y colectiva sujeta al entramado argumentativo subjetivo y a su sostén, complicidad, colectiva.

La dependencia del cachorro humano para su subsistencia es la constante para poder afirmar que, a lo largo de la historia -y, en este punto ni la Antigüedad, ni la Modernidad, ni nuestros tiempos representan una excepción-, los niños se sujetan a las significaciones que los adultos de cada época les otorgan. La discontinuidad se plantea en los modos de sujeción simbólica e imaginaria, según cambien las épocas pudiendo presentarse predominantemente míticos, religiosos, científicos, legislativos. En el mundo en que vivimos, dichas formas no sólo coexisten, sino que su mixtura resulta un aspecto que debemos indagar.

Dicha sujeción permanece incluso en tiempos de guerras y en tiempo de paz, en los procesos migratorios, en los efectos de las enfermedades y epidemias. No hay modo alguno de desestimar cómo los infantiles sujetos quedaron ligados, amarrados a los modos de vivir de los adul- 
tos de la comunidad de la cual se trate, fuera ésta familiar o social, fuera cual fuere la forma de gobierno en cuestión ${ }^{7}$. Se trata, entonces, de analizar las formas de sujeción a los imaginarios que conforman el universo simbólico propio de cada tiempo, en sus diversidades y en las tensiones gestadas por las hegemonías.

\section{INFANCIA Y PSICOANÁLISIS}

La irrupción en el discurso de la noción de infancia freudiana, el hablar y conceptualizar respecto de la "sexualidad infantil" (Freud, 1905) -otorgándole carácter universal- provocó un gran escándalo en su tiempo, adhesiones y críticas, subvirtiendo modelos progresistas y evolutivos al darle condiciones de posibilidad al análisis de la lógica subjetiva.

En términos generales, podemos decir que Freud no define la infancia, sino que establece diferencias entre el "infantil sujeto" y "lo infantil del sujeto". De esta manera, aborda - en diferentes partes de sus Obras Completas- la "vida infantil del sujeto", la "historia infantil", la "inclinación infantil del sujeto", la "fantasía infantil del sujeto" y los "complejos infantiles". Sobre este último punto, plantea expresamente el "descuido de lo infantil" en el devenir del padecimiento humano singular y social. Distingue, asimismo, entre "neurosis infantil" y "neurosis de la infancia" en distintos estudios de su extensa obra, especialmente en sus Lecciones introductorias XXIII (1916-17); Análisis terminable e interminable (1937); Inbibición, sintoma y angustia (1925); Historia de una neurosis infantil VIII; Nuevas Conferencias de introducción al psicoanálisis (1933 [1932]); Moisés y la religión monoteísta (1939 [1934-38]).

Lacan, por su lado, incorpora el término infans para distinguir ese tiempo en el cual el infantil sujeto aún no habla.

El psicoanálisis ubica en el discurso a "niño" como "objeto" sujeto a la lógica del inconsciente; es decir, objeto por tanto del interjuego de la demanda, subjetivante, que va de la alienación a la separación del deseo del Otro.

¿Qué es un niño entonces, desde Freud, para el psicoanálisis? Lacan expone que "niño" es el único "objeto a" y lo dice de esta manera:

No hay otra fuente de la toda-potencia infantil, y no diré las ilusiones que ella engendra de su realidad, que el niño es el único objeto $a$, auténtico, real, inmediatamente a este título él contiene al deseante (1965, 3 de febrero, p. 78) 
Para Lacan "niño" define un concepto trabajado por lo inconsciente en las operatorias y permutaciones simbólicas que instituye el deseo al instituir la ley. En este sentido, resulta fundamental retomar el texto en el cual Lacan intenta socavar el efecto de idealización del "deseo" que algunos, ya cuando escribía Kant con Sade (1966), habían comenzado a manifestar a partir de sus desarrollos. Por lo tanto, advierte las confusiones que homologaran deseo con libertad de goce:

El deseo, lo que se llama el deseo, basta para hacer que la vida no tenga sentido si produce un cobarde. Y cuando la ley está verdaderamente ahí, el deseo no se sostiene, pero es por la razón que la ley y el deseo reprimido son una sola y misma cosa, incluso esto es lo que Freud descubrió. (Ibíd, p. 761-762)

Otras distinciones posibles encontramos en las referencias hacia el "niño" y la "niña" en Lacan, Françoise Dolto, Maud Mannoni o Donald Winnicott (Hartmann, 1993). Tales distinciones se encuentran presentes en relación a la posición del analista en la transferencia respecto del niño/a y sus progenitores (Hillert, 1999).

Hillert señala que cada uno de los analistas mencionados ha hecho su aporte desde su propia posición subjetiva, renunciando a presentarse como modelo y rescatando sus propios estilos.

Ahora bien, como hemos mencionado, tanto sobre el término "niño" como "infancia" recaen diversidad de significaciones que sólo en apariencia implican acuerdos. Ello no resulta sin consecuencias sea en la clínica, en lo familiar, en lo social, en lo jurídico, en lo administrativo, en lo institucional.

Considerar al término infancia como significante implica que la misma será definida desde la posición subjetiva del hablante. Este concepto ocupa un lugar nodal en este trabajo, ya que allí se fija el punto de imposibilidad de una teoría que oficie como modelo y que plantee una posición unívoca. Se trata ni más ni menos que de admitir, con el reconocimiento debido, las diferencias y los efectos que una u otra posición producen respecto de la singularidad del caso del cual se trate.

\section{INFANCIA MODERNA, LA PERSPECTIVA DE FRANÇOISE DOLTO}

El debate en torno a la noción de infancia moderna no resultó ajeno al psicoanálisis. Françoise Dolto (1986) otorga un lugar privilegiado -aunque crítico- a las investigaciones historiográficas de Philippe Ariès. 
Por ellas, indagó en los imaginarios, los ideales, que han sostenido y sostienen los adultos respecto de los niños y las niñas en la modernidad.

Ella intentó expresamente combatir cualquier forma de encierro de la subjetividad infantil en los parámetros normativizantes. En cambio, puso de relieve cómo los efectos de la posición del niño en el fantasma parental, docente, legislativo y social, sustentan y justifican ciertas intervenciones tanto de los analistas de niños como de las instituciones que de un modo u otro se dedican a su educación y/o a su asistencia.

Las ficciones sostenidas respecto de la infancia, hasta la irrupción del discurso freudiano, no consideraban el mundo imaginario de los primeros años y, advierte Dolto, muchos se han quedado en él cuando hablan de la infancia. Abrió el debate denunciando los desvíos que en el propio ejercicio del análisis de niños, en nombre del psicoanálisis, se estaban produciendo, en la segunda mitad del siglo XX.

Consideró que si bien la modernidad instituye la diferencia entre adulto y niño (lo cual, representa una ventaja para el devenir infantil) los imaginarios de infancia moderna no resuelven la posición simbólica del niño en la cultura como sujeto del lenguaje.

La psicoanalista francesa discrepa con la propuesta de considerar a la infancia sólo como un ciclo evolutivo de la vida. A su vez, presenta una postura crítica respecto de las bondades instauradas por los dispositivos modernos y la familia nuclear, incluso, en relación a la diferencia que se instala entre adultos y niños. Rescata el valor de los mitos y rituales de cada época re-significándolos, señalando el alto perjuicio histórico de la impostura de la moral religiosa y de la concepción del pecado-castigo divino, generador de culpabilidad en la constitución subjetiva.

Afirma enfáticamente:

Para el adulto es un escándalo, que el ser humano en estado de infancia sea su igual. Tenemos un mito de progresión del feto, desde el nacimiento hasta la edad adulta, que nos hace identificar la evolución del cuerpo con la de la inteligencia. Sin embargo, la inteligencia simbólica es la misma desde la concepción hasta la muerte (Ibíd p. 13)

Dolto advierte una situación paradojal respecto del "nuevo sentimiento de infancia moderna" por la idealización y sobreestimación de la familia nuclear: el encierro de los conflictos en los acotados lazos del pequeño grupo donde la sexualidad fuera regulada, moralizada y controlada bajo ese esquema. Convoca a revisar las formas de sociabilidad anteriores a la modernidad, las cuales otorgaban mayor movilidad y apertura exogámica. 
Sostiene que el "nuevo sentimiento", este conmoverse con la condición infantil, responde a autores del Romanticismo, compadecidos por las víctimas de un orden establecido, a través de la puesta en escena de una visión sentimental y humanitaria por los personajes de Gavroche, Oliver Twist, David Coperfield. De un modo u otro, Dolto considera que por esta visión romántica se deja de lado el mundo imaginario de los primeros años:

La subjetividad sigue siendo la de los adultos que idealizan su propia juventud. Revancha del escritor literario sobre los clérigos, ellos argumentan lo contrario que la Iglesia: nacemos sin pecado. La que pervierte es la sociedad (Ibíd, p. 36).

Ya en 1981, publicó un capítulo titulado "Los derechos del niño" en su libro La dificultad de vivir. Allí no se ajusta al análisis de la legislación sobre los derechos del niño, sino que plantea un interrogante de compleja respuesta que, por el momento, dejaremos en suspenso:

\begin{abstract}
¿Cuáles son, pues, las condiciones necesarias y suficientes en el ambiente de un niño, para que los conflictos inherentes al desarrollo de cada ser humano puedan resolverse para aquél en forma sana, es decir, creadora; para que el momento decisivo del Edipo y su resolución en la recomposición de los afectos, de las identificaciones y los deseos incestuosos, se abra paso una persona actuante y responsable; para que la angustia de castración ligada al complejo de Edipo desemboque en el abandono de las fantasías arcaicas o perversas, intrafamiliares, y conduzca al sujeto a su expresión en la vida social mixta y la vida cultural simbólica, aceptando sus leyes? (Ibíd, p. 20).
\end{abstract}

La infancia desde la perspectiva de Giorgio Agamben

Giorgio Agamben (2001) le otorga a la noción de infancia otro estatuto que aleja discursivamente la perspectiva de la infancia como invención moderna. En cambio, se dirige a la partitura freudiana sobre los sueños e identifica así la infancia del hombre con el inconsciente (instancia psíquica según la concepción freudiana) y lo inconsciente (como lo reprimido primordial), ubicándose -tal como lo hiciera Lacan- en la lectura del texto freudiano desde la lingüística de Émile Benveniste. De esta manera, plantea que "infancia y lenguaje" parecen remitirse mutuamente en un círculo donde "la infancia es el origen del lenguaje y el lenguaje, el origen de la infancia" (Ibíd, p. 66) Justamente, es quizás en ese círculo donde debamos buscar el lugar de la experiencia en cuanto infancia del hombre: 
Pues la experiencia, la infancia a la que nos referimos no puede ser simplemente algo que precede cronológicamente al lenguaje y que, en un momento determinado, deja de existir para volcarse en el habla, no es un paraíso que abandonamos de una vez por todas para hablar, sino que coexiste originariamente con el lenguaje, e incluso se constituye ella misma mediante su expropiación efectuada por el lenguaje al producir cada vez al hombre como sujeto (Ibíd, p. 66)

Para el filósofo italiano contemporáneo, la infancia instaura en el lenguaje la escisión entre lengua y discurso, la cual caracteriza de manera exclusiva y fundamental al lenguaje del ser humano. Dicha escisión, siguiendo a Benveniste, la plantea entre lo semiótico y lo semántico: entre sistema de signos y discurso. La infancia, la experiencia trascendental de la diferencia entre lengua y habla, le abre por primera vez su espacio a la historia. Sostiene:

Por eso Babel, es decir, la salida de la pura lengua edénica y el ingreso en el balbuceo de la infancia (cuando el niño, según dicen los lingüistas, forma los fonemas de todas las lenguas del mundo), es el origen trascendental de la historia. (Ibíd, p. 74)

Se trata de una experiencia producto de una operación subjetiva que se renueva y, cada nuevo niño/a deberá atravesar, experimentar, a la vez que allí se abre una hiancia donde la fantasía y la imaginación, el fantasear y el imaginar, tendrán un papel preponderante en tanto producciones humanas de experiencia y de cultura.

...experimentar significa necesariamente volver a acceder a la infancia como patria trascendental de la historia. El misterio que la infancia ha instituido para el hombre sólo puede ser efectivamente resuelto en la historia, del mismo modo que la experiencia, como infancia y patria del hombre, es algo de donde siempre está cayendo en el leguaje y en el habla. (Ibíd, p. 74)

Es en este sentido que no puede considerase la historia como un progreso continuo de la humanidad hablante a lo largo del tiempo lineal. La historia es, en esta perspectiva, esencialmente intervalo, discontinuidad, epokhé. Lo que tiene su patria originaria en la infancia debe seguir viajando hacia la infancia y a través de la infancia. 


\section{INFANCIA Y LENGUAJE}

La puesta en relación de los términos infancia y lenguaje, que propone Giorgio Agamben, y la perspectiva del psicoanálisis respecto de la relación del deseo con la ley nos permiten formular las siguientes tesis: La infancia -en tanto significante- es al lenguaje lo que el deseo a la Ley. La infancia fue, es y será un significante siempre en falta de significación.

La institución de infancia por el lenguaje deja como saldo un vacío inaugural, abriendo la hiancia para la constitución del fantasma como modo de respuesta subjetiva en la relación del sujeto al Otro ${ }^{8}$.

Así como la Ley hace al deseo -lo crea-, el lenguaje vehiculiza en el discurso la infancia, la crea al instituirla en la diferencia.

Consideramos desde Lacan al inconsciente estructurado como un lenguaje, regido por las leyes de metáfora y metonimia. Esta posición implica la renuncia a la lógica de progreso -que ha caracterizado a los últimos siglos al pensamiento hegemónico contemporáneo- para dar lugar a otra lógica, aquella que responde a la legalidad del inconsciente y, a las operatorias de inscripción social -ceremonial- de la ley como ordenadora de la subjetividad.

Las operatorias subjetivas de inscripción de la ley se sujetan por una doble vía de circulación singular y colectiva siempre en tensión y sujetas:

- Por un lado, a las vicisitudes y accidentes singulares, implicando para cada nuevo cachorro humano, en tanto objeto $a$ en el fantasma del Otro, ir constituyendo su fantasma, que no es más que la respuesta singular que el sujeto se da a la pregunta enigmática por el deseo del Otro ¿Qué quiere el Otro de mí? (Amigo, 2005 p. 20).

- Por otro lado, a la liturgia de las ceremonias sociales colectivas que ofician de marcos simbólicos de referencia social, estableciendo los modos válidos para cada comunidad en cada tiempo socio-histórico.

En nuestro tiempo, lo que llamamos formas ceremoniales o simplemente ceremonias, se configura desde el aparataje burocrático institucional construido en tiempos modernos, instaladas en los circuitos legitimadores administrativo-burocráticos que ordenan el funcionamiento del sistema. Ello nos lleva a definirlos como instancia discursiva clave donde se encuentra el texto que nos permite hacer de él discurso.

Entonces, si la infancia es al lenguaje lo que el deseo a la ley, tratar al término infancia como un significante nos permite descentrar el análisis de los efectos de sentido promovidos al otorgarle a la infancia la condición de moderna. 
Infancia moderna resulta así el saldo de un significado de infancia que se legitima en el circuito de intercambio simbólico político-académico, el cual se traduce en una definición teórica unívoca acerca de cuál es $L A$ noción de infancia válida, permitiendo -por contraposición y ante los diferentes cambios producidos a lo largo del siglo XX- declamar y declarar el fin de la infancia (moderna) y la aparición de nuevas infancias y adolescencias.

Discursos y prácticas académicas interdisciplinarias contemporáneas, en cuyas derivaciones - presentadas como historia oficial- afianzan los principios de la racionalidad científica moderna, encubriendo su íntima alianza con las teorías económicas que alientan el denominado mercado de consumo, dejan atrapados a los niños en sus redes en tanto consumidores. La puesta en juego de estos enunciados transita en un filo delicado que no carece de consecuencias fácticas.

Sostendremos que, en tanto infancia opera como significante en la singularidad biográfica y, desde allí se proyecta a lo colectivo, el enunciado sobre la caída/fin de la infancia, tanto como admitir a los niños como consumidores, justifica la definición de nuevas infancias y adolescencias, lo cual habilita un campo de desujeción y de des-historización. Allí mismo se desliga a lo infantil que cada uno porta y, además, lo que aparece como nuevo en el comportamiento de los infantiles sujetos, se presenta al modo de lo siniestro, en lo real de la escena.

Llegamos a un punto de encuentro con un absurdo lógico. ¿Es posible para un niño/a no ser nuevo/a respecto de las generaciones que le preceden? Entonces, ¿cuál es la novedad o, mejor dicho, cuál es la discontinuidad o ruptura histórica, cuando el análisis de lo nuevo opaca otras facetas de la infancia moderna, la cual se sostiene en la racionalidad científico-económica-jurídica moderna?

Pareciera que dicha narrativa alimenta, en determinados círculos de legitimación epistémica, la idea de un cierto progreso (i)rracional que nos interesa poner en tensión cuando se instituye la novedad de manera solidaria con la lógica del mercado, acarreando como consecuencia la admisión de la ley del todo vale (propia de esa lógica) respecto de las instituciones filiatorias intergeneracionales.

A causa de lo expuesto, surge entonces como efecto de sentido considerar a la noción de niño como consumidor, subordinada a los cambios tecnológicos y al mercado. Y allí se los abandona, a la deriva.

Intentando encontrar la identidad entre lo anterior y lo actual y, a la vez, tratando de definir el significado de una enunciación nueva, for- 
mulamos que no se trata del fin de la infancia, sino de la renuncia que promueven ciertos discursos de nuestro tiempo a la "Educación" (de Lajonquière, 2000) de la prole humana.

Es decir, se advierte la renuncia a la inscripción filiatoria en el linaje familiar, social, cultural. De este modo, se desplaza dicha inscripción hacia el universo imaginario propio del discurso de la cultura hegemónica de nuestra época, por parte de generaciones de adultos que, desilusionadas con su propia infancia, no acreditan el derecho a la misma en las nuevas generaciones. Esto puede dar lugar a la constitución de la posibilidad de infancias en falta de mitos y leyendas.

Como ya precisamos más arriba, nos interesa lo que queda invisibilizado y, en tanto "lo infantil" (como Freud lo entiende) opera confundiendo:

cómo piensa la infancia aquel que la reconstruye, que la historiza, desde un tiempo Otro, donde la infancia ya no es - siendo y,

cómo piensan los niños, cuáles son sus propias teorías respecto de su acontecer, las cuales difieren a la infancia del presente, proyectándola al tiempo que aún no es.

De acuerdo con la línea de trabajo planteada, debemos orientarnos hacia los modos de inscripción de la legalidad que instituye infancia, destacando la vigencia de lo que Freud (1905) denominara como "teorías sexuales infantiles", otorgándoles un valor estructurante en la lógica subjetiva en tiempos de su constitución.

La distinción se actualiza, además, en lo inherente a la diferencia -y no supremacía- entre "lenguaje adulto y lenguaje infantil"; entre el "lenguaje de la ternura y el lenguaje de la pasión" (Ferenczi, 1932). Estas cuestiones no pueden confundirse sin severas repercusiones subjetivas y sociales.

\section{LA INFANCIA ES AL LENGUAJE, LO QUE EL DESEO A LA LEY}

Si sostenemos el enunciado la infancia es al lenguaje lo que el deseo a la Ley, debemos distinguir la inscripción de la legalidad subjetiva respecto de la letra del texto jurídico para poder ubicar la tensión posible entre la una y la otra.

Se trata de la cuestión de la relación del sujeto al Otro, portador del tesoro de significantes, portador de la legalidad de la cultura; es decir Otro -Tercero social de la palabra (Legendre, 1974) - vehículo del univer- 
so simbólico en el cual la cuestión de la infancia opera. Eso llamado sociedad, afirma Legendre, se sostiene en los montajes institucionales que normativizan ficciones y ofrecen el marco social simbólico de producción de subjetividad.

En este sentido, las cuestiones vinculadas a las legislaciones e instituciones modernas sobre los menores de edad se han mimetizado con las improntas de la ley encarnada en una paternidad fallida, tal es el caso del patter, institución jurídica del Derecho romano que condensa en la figura del padre los dos principios fundantes de la ley jurídica de Occidente: "propiedad y paternidad" (Kozicki, 2004). Ambos principios se han homologado y consolidado no sin severas consecuencias subjetivas y colectivas en torno a la discrecionalidad de las decisiones.

La disyunción inherente a la lógica intrínseca al derecho -entre la letra de la ley y la aplicación de la misma por parte de los representantes judiciales- exhibe una distancia donde habitan las decisiones, las cuales investidas del valor simbólico que se otorga a la figura del juez, oficiarán de hecho como ley más allá de la letra jurídica. Será por las decisiones de los representantes del Tercero social de la palabra que se vehiculiza el marco simbólico donde la ley opera, implicando el análisis de la "fuerza de ley" (Derrida, 1997; Agamben, 2003) que de las mismas emanan.

A pesar de las profundas transformaciones acaecidas desde aquellos tiempos romanos, a nuestra contemporaneidad no le resultan ajenos los principios de propiedad y paternidad, aunque sus formas de presentación se experimenten de manera lejana, en formas de sujeción en la relación a un Otro no barrado, no atravesado por la ley del no-todo-es-posible.

Pierre Legendre (1989) advierte que:

Si bien el discurso moderno sobre el padre, poco a poco ha logrado desprenderse de las consideraciones político-históricas o moralistas, que mezclan familia patriarcal y principio de paternidad, todavía queda atascado en "un pantano de ideas más rígidos que rigurosos" a las cuales adjudica el hacer olvidar la radicalidad de los riesgos entre padre e hijo. Dichos riesgos, sólo son metabolizables bajo la égida de los montajes de la filiación, que consisten en la forzocidad institucional del sujeto. (p. 37)

El tema es objeto de debate abierto. ¿A qué refiere la radicalidad de los riesgos entre padre e hijo? ¿Cuáles son los montajes de la filiación en nuestros tiempos? ¿Cuál es el andamiaje simbólico donde transita eso llamado filiación? Hablar de filiación implica ingresar en el complejo campo del amor y la identificación en su relación a la legalidad del lenguaje. 
Los postulados de Legendre han sido cuestionados por Roudinesco (2003), quien lo considera "creador de una antropología dogmática". Sus críticas apuntan al hecho de darle al marco simbólico-jurídico-normativo el lugar de fortalecimiento de las figuras familiares - materna y paterna heterosexuales- un lugar fundante en el orden social. El acento puesto en las "figuras" materna y paterna implicaría que -en caso de parejas homosexuales- se alteren las referencias diferenciadas del hombre y la mujer. De acuerdo con su enfoque, Legendre vería en las instituciones judeocristianas montajes simbólicos que permiten a los hombres luchar contra los estragos del goce ilimitado, del individuo "sin tabúes" y del niño rey. Advierte que:

...por eso atribuye al Estado democrático moderno, heredero de esas instituciones, el deber de imponer a sus miembros un orden simbólico cuya función consistiría en salvaguardar las referencias diferenciadas del hombre y la mujer. Desde este punto de vista, la madre y el padre son las imágenes fundadoras de la sociedad -y, por lo tanto, de la familia- instituidas por el derecho. (Ibíd p. 209).

Ahora bien, si hablamos de infancia, producto de la institución del lenguaje que sostiene los montajes de la filiación, una pregunta insoslayable resulta la que oriente hacia los efectos paradojales de la inscripción en el orden jurídico del concepto de niño/a como sujeto de derecho. Es decir, ¿es posible desmontar la filiación simbólica sujetando a las nuevas generaciones, filiándolos imaginariamente al derecho cuando su letra sostiene los ideales que definen una moral de época??

Nos encontramos ante paradojas que debemos plantear cuando, por efecto de discurso, el enunciado "niño/a sujeto de derecho" posibilita admitir la des-afiliación a una genealogía que ordene las vías de la filiación, desplazándola a una "anomia"10 jurídica e institucional que, en el amplio margen que deja a las decisiones de la Administración, crea el marco simbólico para la discrecionalidad del Otro social.

No podemos desconocer el modo en que, a través de diversidad de ficciones teóricas, se desvía la posibilidad de otorgar siquiera cierta eficacia simbólica al límite jurídico que la misma letra de la Convención internacional sobre los derechos del niño ${ }^{11}$ impone.

Dicha paradoja refleja la íntima solidaridad con la ilusión de una vida sujeta a derecho cuando, de hecho, reina el Estado de excepción como paradigma de gobierno (Agamben, 2004). Alianza epistémica con las ficciones teóricas que enfatizan las "transformaciones" subjetivas homologándolas con las tecnológicas. 
Si nos hallamos ante un desvanecimiento del soporte simbólico de la Ley primordial, no pueden no ser afectados los lazos intergeneracionales. Tampoco puede dejar de advertirse cómo se llega al extremo de connotar a "niño" en tanto concepto inconexo de cualquier filiación, interpretando la posición del niño en el texto jurídico como de-sujetado a la filiación y, por ende, de la ley de la cultura -la prohibición del incesto-, así como de las formas de intercambio que ella regula. La prepotencia que ha ganado el "sindrome de alienación parental" es una de las referencias más claras al respecto, dado que no es la letra de la ley la que oficia como límite, sino, un supuesto epistémico, económico y académico por demás discutible, que ha dado sustento a la nueva ley nacional de "revinculación del progenitor no conviviente" No. 24270.

Veremos cómo se afianza la creencia en la sujeción-supuesta-aderecho cuando, de hecho, resulta sostenida y justificada por supuestos disciplinares que apuntan a la destitución de las operatorias que puedan inscribir un orden filiatorio y genealógico al linaje propio de lo humano, constituido e instituido por el lenguaje.

Las derivas de la cuestión para los infantiles sujetos no resultan sin consecuencias cuando, por un lado, la discrecionalidad de las decisiones sigue vigente y, por otro lado, queda establecido un lugar vacante donde no hay quien responda por los actos del niño y de la niña desde la más temprana edad. Asimismo, no hay a quien dar cuentas, no hay a quien responder por los propios actos como Otro significativo.

Como consecuencia de ello - del lado del niño y de la niña-, las preguntas que suponemos como constitutivas de la relación al Otro se transforman. Ya no será ¿qué quiere el Otro de mí?, sino ¿a quién le importa lo que haga? y/o ¿qué más debo hacer para ser tenido en cuenta? Desde esta posición, surge el interrogante acerca de cuáles son las condiciones de posibilidad de la operatoria de inscripción, de sujeción del infantil sujeto a la ley, a la cultura, ante el desfallecimiento de la eficacia simbólica de la ley y sus efectos concomitantes, la producción de desamparo subjetivo.

Se impone avanzar e interrogar si resulta posible para la continuidad humana en la cultura estar des-afiliada intergeneracionalmente, es decir no ser la infancia, institución del lenguaje.

Entonces, comprender que la infancia -en tanto significante- es al lenguaje lo que el deseo a la ley, implica aclarar ciertas confusiones que provoca el uso del concepto de ley, tanto dentro como fuera del marco epistémico psicoanalítico, especialmente cuando ha quedado amalgamado al orden del derecho como si ello fuera algo natural y no una producción discursiva de larga data en lo que se define como Occidente. 
A partir del discurso freudiano, en relación con la ley es necesario distinguir el discurso de la ley respecto de la ley primordial. El sujeto encuentra su lugar en un aparato simbólico preformado que instaura la ley en la sexualidad.

Lacan, por su lado, sostiene:

Freud introdujo la castración de forma totalmente coordinada con la noción de ley primordial, lo que la prohibición del incesto y la estructura del Edipo tienen de ley fundamental. Este es, si lo pensamos ahora, el sentido de lo que Freud enunció de entrada. Cuando Freud situó una noción tan paradójica como la de la castración en el centro de la crisis decisiva, formadora, principal, que es el Edipo, lo hizo entrando en la experiencia con una especie de salto mortal.

Retrospectivamente este hecho no puede sino maravillarnos, porque sin duda es maravilloso que todo lo que se nos ocurra sea no hablar de ello. La castración sólo puede clasificarse en la categoría de la deuda simbólica.

Deuda simbólica, daño imaginario y agujero o ausencia real, he aquí como podemos situar estos tres elementos que llamaremos los tres términos de la falta de objeto. (1956 p. 39)

Consideramos como un hecho de estructura que el humano, en tanto parlante, siempre está en posición de no comprender nunca por completo la ley,

... porque ningún hombre puede dominar en su conjunto la ley del discurso (Lacan, 1955 p. 197).

Referir a la Ley primordial implica aludir a lo real; es decir, a aquello que se inscribe en el orden del discurso por la prohibición como marca simbólica de la diferencia; prescribiendo, además, que lo real será un territorio de inaccesibilidad, habilitando la escritura del sujeto deseante. Este límite establece en la doble prohibición - del incesto y del homicidio- la condición de posibilidad del reconocimiento de la alteridad, del lazo social en la cultura. La Ley instituye el deseo en tanto prohibido y habilita un orden de intercambios regulados.

De la ley tenemos noticias por el marco simbólico que, al tiempo que demarca un territorio de inaccesibilidad, habilita la dimensión de la vida, reflejando de ese modo este carácter fundante de la ley como instrumento mayor de humanización: 
La ley es portadora de un elemento de extrañeza, del orden del enigma, es decir siempre abierta a interpretación. En consecuencia, sólo podemos ensayar aproximaciones indirectas, oblicuas, a la manera oracular. El enigma, por hipótesis, está llamado a no ser develado, ése es su ser. [...] La ley es la función destinada a limitar a cada sujeto. Lo jurídico constituye la marca de lo simbólico que inyecta-inflige la Ley, en tanto límite, en los seres humanos, instituyéndolos como sujetos (Kozicki, 2004, p 80-81).

Kozicki considera el marco jurídico del derecho como el máximo exponente de las metáforas de la ley (siguiendo en la misma línea del pensamiento de Pierre Legendre). Sin embargo, advierte cómo algo viene sucediendo respecto del soporte jurídico de la ley, en tanto legislador de lo humano en la cultura:

Las formas que se sirve metafóricamente del meollo jurídico del vocabloconcepto ley, que lo toman prestado, contribuyen, por vía indirecta, a poner aún más en evidencia, precisamente, ese meollo jurídico, ese núcleo duro. Esas leyes son, insistimos, metáforas, y, en tal carácter, tributarias del concepto jurídico que les sirve de nombre, de soporte. Hemos pasado de la serena reflexión de Claude Bernard: 'La Ley nos da la relación numérica del efecto con su causa', a la irrupción de la Ciencia en la escena pública arrogándose una función normativa que no es la suya, por una parte, y, por la otra, proclamando leyes científicas a rolete. Una cosa es servirse de la Ley como metáfora (ley de la gravedad, leyes de la herencia, ley de los grandes números, ley de la oferta y la demanda), como una fórmula general, metafórica, no imperativa, enunciando una relación constante entre fenómenos, y otras, muy distinta, es que la Ciencia y la Economía ultramodernas pretendan sustituir, desplazar, a la Ley, privándola de su radical función de límite en tanto instrumento mayor de humanización”. (Ibíd, p. 83)

\section{INFANCIA E INSTITUCIÓN(ES)}

Debemos precisar el sentido que damos al término institución ${ }^{12}$, distinguiéndolo del sentido jurídico que ha tenido y aún conserva. Nos proponemos recuperar su valor en términos de la escritura de la ley en la configuración subjetiva, en el marco epistémico que nos brinda el psicoanálisis.

Hablaremos de institución para designar la marca simbólica de la diferencia que inscribe al hablante en la legalidad del lenguaje. En este sentido, la institución será considerada como la dimensión legislada de la vida. Desde esta perspectiva será preciso analizar los efectos de discurso que promueve la tan mentada des-institucionalización. 
Así como se impone distinguir el enunciado dimensión legislada de la vida respecto del orden jurídico, debemos también diferenciar dimensión jurídica de la vida e institución, puesto que señalan dos órdenes de la cuestión, que se reúnen y distancian cuando de la relación del Sujeto a la Ley se trata.

Nos interesa destacar cómo el discurso que liga vida y norma, hecho y derecho, desdibuja y naturaliza tanto la relación del sujeto a la norma como la distinción necesaria entre el hecho y el derecho, lo cual habilita el análisis de esa doble condición propia e intrínseca a este último que plasma la distancia lógica, a su vez, entre la norma y su aplicación.

La institución en esta red argumentativa significante no refiere a las organizaciones institucionales, sino al texto de sus saberes y prácticas. Debemos dirigirnos a los dichos encriptados, a fin de promover la posibilidad de relanzar el análisis del tema. Se trata de desarticular saberes instituidos que ofician como dichos signados como destino ${ }^{13}$ para abrir el juego, ubicando a la institución como marca simbólica de la diferencia. Ello nos conduce a las formas de escritura de ley inherentes al hablante.

Si hablamos de marcas, ellas no pueden no ser simbólicas ya que devienen de operaciones de lenguaje regidas por la legalidad del inconsciente: condensación y desplazamiento (Freud) -metáfora y metonimia (Lacan) - en una movilidad incesante de diacronía y sincronía donde la temporalidad del sujeto es posible de ser medida por sus marcas, es decir, por los cortes sincrónicos en la continuidad diacrónica, más allá de cualquier medición cronológica en la línea que liga nacimiento y muerte ${ }^{14}$.

Pensar la infancia como marca simbólica de la diferencia nos remite a las formas de sostén colectivo en falta respecto a su institución.

Siguiendo la línea de pensamiento que plantea el devenir de la teoría de Agamben, infancia instituida será aquella legislada por la escisión fundante que abre la hiancia entre lengua y discurso; lengua y habla; entre lo semiótico y lo semántico, haciendo del sistema de signos, discurso donde se produce el interjuego de lo Uno y lo múltiple en la articulación significante.

Será entonces que instituir implique dejar por fuera, dejar ex - sistente lo Uno: lo real, habilitándose en esa escisión el hiato para las operaciones del lenguaje regidas por la legalidad del inconsciente desde donde se producirá -en la relación del infantil sujeto al Otro- la configuración del fantasma en y desde el campo del Otro. ¿Por qué hablar del fantasma? Porque el fantasma auxilia al sujeto ante el encuentro con lo real. Nos asegura "contar con el marco del agujero a lo real"15. Interesante cómo Lacan 
escribe que "Lo real es soporte del fantasma, el fantasma protege a lo real" (1964, 29 de enero p. 49).

Instituir infancia como dimensión legislada de la vida no puede ser un proceso ni exclusivamente singular ni exclusivamente colectivo, sino que está sujeto tanto a las vicisitudes propias a cada singularidad como a las formas ceremoniales colectivas que legislan el pasaje por las operatorias de inscripción de la ley en la cultura.

Será en la liturgia de dichas ceremonias que podamos encontrar las creencias predominantes, que aun transformándose de acuerdo con las épocas, vehiculizan los imaginarios que los ya residentes de este mundo sostienen respecto de los nuevos. Allí se encuentran las metáforas que sostienen los unos respecto de los otros.

Desde nuestra perspectiva, en los tiempos que corren este posicionamiento resulta clave, ya que por efecto de lo que se supone una creación e invención modernas (Ariès, 1973), la noción de infancia y los imaginarios que de ella derivan, la han dejado asociada a la Modernidad y escindida de su otra faceta institucional discursiva y fáctica: Minoridad. La niñez moderna pasó a ser entendida como una producción de sentido sobre el devenir de niñez institucionalizada, escindiéndose los circuitos de intercambio legitimadores administrativo-burocráticos en dos vías institucionales marcadas Educación y Minoridad. Esto produjo dos categorías para los infantiles sujetos: niños y menores ${ }^{16}$.

La Niñez Moderna -sujeta al texto normativo jurídico, educacional y científico-psicológico- normaliza y cristaliza un deber ser de los primeros tiempos de la vida humana, el cual se ve sometido a sus propias reglas discursivas que hablan y definen saberes sobre la infancia; saberes sostenidos en "ilusiones (psico)pedagógicas" (de Lajonquière, 2000a y 2000b).

Infancia, en tanto significante siempre en falta de significación, no admite ser capturado en campo de sentido unívoco alguno, sino que requiere continuar representando el intercambio en la línea de las generaciones y ligando la continuidad y discontinuidad de cada uno con su propio antepasado, así como las continuidades y discontinuidades que renuevan el juego diacrónico y sincrónico de la historia humana.

Se trata de recuperar el valor que otorga instituir infancia en discursos y prácticas contemporáneas, en relación con la legalidad de la cultura, por la inscripción de la Ley fundante del sujeto en el orden social. Inscripción que implica sujeción a una genealogía, posibilitando al sujeto ser producto y productor de una historia humana que pueda tener continuidad en el mundo. 
Resulta casi patético (pathos) reconocer, en nuestros tiempos, cómo el infantil sujeto, en busca de deseo de deseo y, en su afán de hallar un Otro que le otorgue el auxilio que le hace falta en su desvalimiento, queda capturado en la arbitrariedad, como partenaire impecable de aquel que lo requiere para satisfacer su libertad de goce.

Infancia instituida, será producto en lo singular, del pasaje por la operación metafórica de la castración. Ese pasaje -siempre pasible de accidentes- requiere de su correlato y sostén colectivo, para que los dos tiempos mistificación-desmitificación puedan encontrar el soporte simbólico-imaginario que bordee a lo real de la Cosa.

Estas vías argumentativas nos conducen a la intrincada y compleja relación entre lo colectivo y la singularidad del sujeto, tema que dejamos abierto.

\section{NOTAS}

${ }^{1}$ Este trabajo es parte de la tesis doctoral inédita Infancia, Derechos del niño y Psicoanálisis, Facultad de Psicología Universidad Nacional de Rosario, Argentina.

This work is part of the original doctoral thesis named Infancia, Derechos del niño $y$ Psicoanálisis, Facultad de Psicología Universidad Nacional de Rosario, Argentina.

${ }^{2}$ Seguimos en este sentido la definición que le otorga Nasio (1994). Decires puede también traducirse por "significantes"; "significantes reprimidos" "cadena de significantes reprimidos". El dicho es algo que tiene valor de acto.

3 Gerez Ambertín en "Las torpezas: el ofrecimiento sacrificial y la angustia" distingue dos acciones sacrificiales: a) aquella que deja como saldo un ahorro del sacrificio y de la angustia dado por la efectividad del ofrecimiento del don al Otro deseante, por la posibilidad de implicarse subjetivamente en ese acto y b) cuando se produce ahorro del sacrificio, y el sujeto queda hipotecado al destino cruel con el ofrecimiento de por vida de una "libra de carne" al Otro del goce.

${ }^{4}$ Discusión por demás interesante que Loyd de Mauss (1982) habilitara a partir de poner en tela de juicio la tesis de Philippe Ariès (1973) quien otorga a la Modernidad una nueva sensibilidad hacia la niñez nunca antes planteada. De Mauss demuestra que sólo una ilusión puede sostener los argumentos de Ariès. El mismo Ariès en el prólogo a la segunda edición de su libro (1987) rectifica su postura reconociendo que, si volviera a escribir su libro, pondría el acento en la tolerancia al infanticidio también presente en tiempos modernos.

${ }^{5}$ Dolto (1986); Hartmann (1993); Agamben (2001); Cicerchia (1998a y 1998b); Cauvilla (1999); de Lajonquière (1998; 2000a; 200b; 2005); Delgado Criado (2000); Donzelot (1999); Roudinesco (2000); Coraza (2001); Kohan (2004); Volnovich (1999 y 2000).

${ }^{6}$ Concepto que ha ganado terreno incluso en el campo educativo, al ser considerado como el título de la Carrera de Especialización propuesta por el Ministerio de Educación destinada a profesores de nivel superior terciario (formadores de docentes). La denominación es Carrera de Especialización en nuevas infancias y adolescencias. (2006). 
${ }^{7}$ Pensemos en el destino del hijo/a de un monarca contemporáneo. En el año 2005 nace la hija del príncipe heredero de la corona española. Siendo una niña la primogénita, debe reformarse la constitución, tarea que han decidido emprender para abandonar el lugar prioritario del primogénito varón.

${ }^{8}$ Sostiene François Balmès (1999) que "La invención del Otro (A) en Lacan, constituirá el vínculo común de aquello que en Freud se presenta como metapsicología y el conjunto formado por los enunciados el padre [...] Este Otro surge en Lacan a partir del axioma fundador del inconsciente estructurado como un lenguaje y de una interrogación sobre la estructura que está en juego en la palabra (que dio lugar al establecimiento del esquema L.) Presupone la distinción de lo Real, lo Simbólico y lo Imaginario, puntos todos ajenos a Freud." (p. 31). A su vez, debemos considerar que "Entre las vueltas de la vida y la relación con un "determinado" Otro, mezcla estructural en la cual cada quien se forja, surge o no, un modo de respuesta fantasmática”. (AMIGO, 2005 p. 22)

${ }^{9}$ La cuestión ha sido objeto de tratamiento en nuestra investigación preliminar, Minnicelli, 2004. A su vez, la posición de los términos "niño y menor" en el texto jurídico ha sido analizado por Degano, 2005. Producto del rico intercambio con el autor se han ido generando hipótesis que habilitaron la posibilidad de nuevos interrogantes que surgen, también, a partir de la lectura de su texto.

${ }^{10} \mathrm{El}$ concepto de anomia, fue introducido por Durkheim en el campo de sociología aunque sus antecedentes nos remontan a Herodoto de Alicarnaso (484-406 a.C.), quien lo usó cuando se refirió a la guerra entre griegos y persas.

Hilda Eva Chamorro Greca de Prado en su trabajo "El concepto de anomia, una visión en nuestro país” plantea que el concepto ha tenido un uso religioso, ya que también en la Antigüedad se incluye el concepto de anomia sobre todo, en el Antiguo Testamento. En las traducciones fue intercambiado por "hamartia", en ambos casos para significar “pecados”. En Grecia, significó lo malo, lo perverso, la falta de orden social, la desesperación, toda forma de vicios. En 1688, Vico en su Cátedra de Ética decía: "La edad de los hombres inicia su decadencia cuando los seres humanos dejan de respetar la ley, cuando la licencia descompone la igualdad y cuando la filosofía sucede a la religión”. La autora expone que después de dos siglos de silencio con respecto a la anomia, aparece en el siglo XIX con los filósofos franceses, sin connotaciones religiosas, como una expresión correspondiente a la ética. Ubica el nuevo uso del término, resignificado, en la monografía de Durkheim sobre El suicidio (1897) en el debate entre el "realismo" de Durkheim y el "nominalismo" de Jean Marie Guyau y de Tarde. (3 de mayo de 2005, conferencia. Academia Nacional de Derecho y Ciencias Sociales de Córdoba. Argentina. En www.acader.unc.edu.ar).

Si bien somos herederos de dicho concepto, la correlación que establece Durkheim entre la disminución de la acción reguladora de la sociedad y, el aumento de tasas de suicidio equivaldría en el decir de Agamben (2003) a tener que admitir una necesidad de los seres humanos de ser regulados en sus actividades y en sus pasiones. "De este modo, no sólo se da por descontada la ecuación entre anomia y angustia (mientras que, como veremos, los materiales etnológicos y folclóricos parecen mostrar lo contrario), sino que además la posibilidad de que la anomia tenga una relación más íntima y compleja con el derecho y con el orden social es neutralizada de entrada". El problema de fondo es el de los efectos en la subjetividad del orden social y viceversa que, no debemos confundir con la ley en la estructura. 
${ }^{11}$ Se presenta en anexo el texto completo de la Convención sobre los Derechos del Niño y de la Ley Nacional No. 26061.

${ }^{12}$ A lo largo del siglo XX el concepto de institución ha sido controvertido, dando lugar a sendos debates de distinto orden filosófico y político, confluyendo en la configuración de diferentes teorías institucionales tal como las puntualizara en la década del '70 René Loureau en el ya clásico Análisis institucional (1970). Las derivas del tema son diversas y de una magnitud de desarrollos que merecerían, en sí mismos, un despliegue exhaustivo que nos excede.

${ }^{13}$ De acuerdo con Assoun (2001) "lo que contiene el 'destino' -la Moira o heirmamené griega, el Fatum de los latinos, el Schicksal germánico- es la idea de un "poder" que se ejerce sobre el sujeto y se impone a su historia -la "super-visa"- de manera que "ciertos acontecimientos estarían determinados de antemano, suceda lo que suceda. Es comprensible que el destino tenga dos opuestos: como es irrevocable, se opone a la libertad; como está programado, se diferencia del azar - dualidad de Ananké y de Tyché-. A su vez se pregunta ¿cómo influir en esta idea del destino, en su "contenido de cosa" (Sachverhalt) inconsciente?” (p. 66 y sig.)

${ }^{14}$ "Hay que entender el alcance de esta relectura que Freud hace del "tríptico destinal" del sujeto. Entre su destino interno (el del registro "constitucional"), es decir lo que trae con él y que no lo abandonará nunca del todo y su destino externo (la muerte que lo espera al final del trayecto), se inserta el registro de lo "vivido" (Erbelen). Ahora bien, vivir es, entre estos dos destinos, desarrollar también un destino, pero susceptible de... Zafall. "Vivir" significa que me puede pasar algo. Esto es justamente lo que abre la dimensión de lo real, también en sus connotaciones traumáticas". (Assoun, 2001 p. 82 y s.s.)

Ahora bien, en ese intervalo, expuesto al riesgo y a la "dificultad de vivir", en el acontecimiento mismo del deseo, puede pasarme algo que es irreductible al destino: esto es el "encuentro", "bueno" o "malo", "malo y bueno", es decir entre "suerte" y desgracia", amor y síntoma. Bajo la seducción de la tyché, dustukia bruta que es el "trauma" y tiende a "refractarla" en ese dispositivo automático que es el lenguaje".

${ }^{15}$ En este sentido, Silvia Amigo (2005) plantea que "el marco del agujero permite hacer entrar y salir al objeto. Hacerlo entrar en la ilusión de retenerlo, ilusión normativa necesaria, y hacerlo salir en el momento de dejarlo ir, momento necesario para fundar la ley simbólica de intercambio, de lazo social”. (p. 60)

${ }^{16}$ El tema ha sido ampliamente desarrollado en Minnicelli (2004)

\section{BIBLIOGRAFÍA}

AGAMBEN, G. [1997] Infancia e Historia. Buenos Aires: Adriana Hidalgo, 2003.

AGAMBEN, G. Estado de excepción. Buenos Aires: Adriana Hidalgo, 2004.

AGAMBEN, G. Profanaciones. Buenos Aires: Adriana Hidalgo, 2005.

AMIGO, S. Clínica de los fracasos del fantasma. Rosario: Homo Sapiens, 2005.

ARIÈS, P. [1973] El Niño y la vida familiar en el Antiguo Régimen. Madrid: Taurus, 1987.

ASSOUN, P-L. El fetichismo. Buenos Aires: Nueva Visión, 1995.

ASSOUN, P-L. El perjuicio y el Ideal. Hacia una clínica social del trauma. Buenos. Aires: Nueva Visión, 2001.

BALMÈS, F. El nombre, la ley, la voz. Freud y Moisés: escrituras del padre 2. España: Del 
Serval, 1999.

CAUVILLA, W. Sobre um momento da constitução da idéia de infância: ponto de vista de um historiador. Estilos da Clínica. Revista sobre a infancia com problemas. Instituto de Psicología. Universidade São Paulo, 4 (6) 72-79, 1999.

CICERCHIA, R. Minors, Gender, and Family: The Discourses in the Cpurt System of Traditional Buenos Aires. The History of the family An International Quarterly, 2 (3) 331346, 1997.

CICERCHIA, R. Historia de la vida privada en la Argentina. Buenos Aires: Troquel, 1998a.

CICERCHIA, R. (Comp.) Formas familiares, procesos históricos y cambio social en América Latina. Quito: ABYA-YALA, 1998b.

CORAZA, S. História da infância sem fim. Rio Grande do Sul: UNIJUI, 2001.

DE LAJONQUIÈRE, L. De Piaget a Freud. Para repensar los aprendizajes. Buenos Aires: Nueva Visión, 1997.

DE LAJONQUIÈRE, L. La educación de los niños, el hombre moderno y el psicoanálisis. Cuaderno de Pedagogía. Rosario: Centro de Estudios en Pedagogía Crítica, 5 (3) 63-83, 1999.

DE LAJONQUIÈRE, L. Infancia e ilusión (psico)pedagógica. Buenos Aires: Nueva Visión, 2000a.

DELGADO CRIADO, B. Historia de la infancia. Barcelona: Ariel, 2000.

DEMAUSE, Ll. Historia de la infancia. Madrid: Alianza Universidad, 1982.

DOLTO, F. [1986] La Causa de los niños. Buenos Aires: Paidós, 1996.

DONZELOT, J. [1977] La policía de las familias. España: Pre-Textos, 1990.

FENDRIK, S. Psicoanálisis para niños. Ficción de sus orígenes. Buenos Aires: Amorrortu, 1989.

FERENCZI, S. [1932] Confusión de lengua entre los adultos y el niño. El lenguaje de la ternura y el de la pasión. Conferencia presentada en el XII Congreso Inernacional de Psicoanálisis, 1932.

FREUD, S. [1905] Tres ensayos de una teoría sexual infantil. Op. cit. Tomo VII

FREUD, S. [1915] De guerra y muerte. Op. cit. Tomo XIV

FREUD, S. [1920] Más allá del principio de placer. Op. cit. Tomo XVIII

FREUD, S. [1932-1936] Nuevas Conferencias de introducción al psicoanálisis. Op. cit. Tomo XXII

FREUD, S. [1939 [1934-1935]] Moisés y la Religión Monoteísta. Op. cit. Tomo XXIII

FREUD, S. [1937] Análisis terminable e interminable. Op. cit. Tomo XXIII

FREUD, S. Nasio, J. D. El magnífico niño del Psicoanálisis. El concepto de sujeto y objeto en la teoría de Jacques Lacan. Barcelona: Gedisa, 1994.

HARTMANN, A. En busca del niño en la estructura. Estudio psicoanalítico de la infancia y su patología. Buenos Aires: Manantial, 1993.

HILLERT, R. Niños y analistas en análisis. Rosario: Homo Sapiens, 1994.

KOHAN, W. Infancia, entre Educación y Filosofía. Barcelona: Laertes, 2004.

KOZICKI, E. Clases dictadas en el Curso de Doctorado "La Ley en Cautiverio". Facultad de Psicología Universidad Nacional de Rosario. Mimeo, Rosario, 2002.

KOZICKI, E. De la dimensión jurídica de la vida. Derecho y Psicoanálisis. Buenos Aires: Hachette, 1987.

KOZICKI, E. La filiación. El HLA, el ADN. La Ciencia y el Derecho. Buenos Aires: LA LEY, 27 de julio, 1990.

KOZICKI, E. Derecho y psicoanálisis. Revista de la Asociación de Psicólogos Forenses de la 
República Argentina, (2), 1992.

KOZICKI, E. Por amor al Jefe. Exorbitancia y erotismo del poder. Revista del Colegio Público de Abogados de la Capital Federal. enero-febrero, 1998.

KOZICKI, E. Law and Economics. ¿La vida o la.bolsa?. En Buenos Aires: LA LEY, 23 de febrero, 1999.

KOZICKI, E. Hamlet, el Padre y la Ley. Buenos Aires: Gorla, 2004.

LACAN, J. [1954-1955] El Yo en la Teoría de Freud y en la Técnica Psicoanalítica. Seminario 2. Buenos Aires: Paidós, 1992.

LACAN, J. [1956] Las relaciones de objeto. Seminario 4. Buenos Aires: Paidós, 1994.

LACAN, J. [1957-1958] Las formaciones del inconsciente. Seminario 5. Paidós, 1999.

LACAN, J. [1958-1959] El deseo y su interpretación. Seminario 6. Inédito. Versión electrónica (V. e.).

LACAN, J. [1959-1960] La ética del Psicoanálisis. Seminario 7. Paidós, 1997.

LACAN, J. [1964] Los cuatro conceptos fundamentales del Psicoanálisis. Seminario 11. Paidós, 1993.

LACAN, J. [1965] Clase del 3 de febrero, edición electrónica.

LEGENDRE, P. La crisis del juridismo. El discurso jurídico. Perspectiva psicoanalítica y otros abordajes epistemológicos (Entrevista de Enrique Kozicki). Buenos Aires: Hachette, 1982.

LEGENDRE, P. La 9010. Conclusión, ëtude sur le théatre de la Raison. Paris: Fayard, 1998.

LEGENDRE, P. [et. al] El discurso jurídico. Perspectiva psicoanalítica y otros abordajes epistemológicos. Buenos Aires: Hachette, 1982.

LEGENDRE, P. El amor del censor Madrid: Anagrama, 1974.

LEGENDRE, P. El inestimable objeto de la transmisión. Estudio sobre el principio genealógico en Occidente. Paris: Fayard. Méjico: Siglo XXI Editores, 1985.

LEGENDRE, P. El crimen del cabo Lortie. Tratado sobre el padre. Lecciones VIII. Madrid: Siglo XXI Editores, 1994.

MINNICELLI, M. Infancias públicas. No hay derecho. Buenos Aires/México: Novedades Educativas, 2004a.

VOLNOVICH, J. Los cómplices del silencio. Infancia, subjetividad y cultura. Buenos Aires: Lvmen-Hvmanitas, 1999.

VOLNOVICH, J. Abuso sexual en la infancia. Buenos Aires/México: Lvmen- Hvmanitas, 2002.

VOLNOVICH, J. C. El niño del 'siglo del niño'. Buenos Aires: Lvmen- Hvmanitas, 1999.

Recebido: 30/09/2008

Aprovado: 01/10/2008

Contato:

Facultad de Psicología

Funes 3250

Mar del Plata (7600)

Provincia Buenos Aires

ARGENTINA 